Research Protections would be an obvious place to begin. Another improvement would be more widespread accreditation of the IRBs, to help ensure proper training and support for committee members.

But further reforms are also necessary. Some see centralizing the review of multicentre studies as a way of relieving the burden on local review boards. But the debate over whether to centralize, or even regionalize, the review of studies is complex. The United States is a large, diverse and, most of all, litigious country, and local boards help universities to fend off legal action by showing that they have taken responsibility for what goes on within their walls. Nonetheless, centralization deserves to be explored further.

One approach would set up national committees, perhaps run by the National Institutes of Health, that could establish clearer guidelines on the ethical quandaries commonly faced by local review boards. Questions over payments to volunteers, for example, or on what constitutes informed consent, need not all be answered on the current ad hoc basis.

Another challenge facing US authorities is the fact that not all research on human subjects is overseen by the federal government. The
IRBs are not federal, but federally funded research on human subjects must be reviewed by them, as must any trial that becomes part of a submission to the Food and Drug Administration. Some states and institutions also require all research on human subjects to be vetted by an IRB. That leaves room for privately funded research to proceed without any requirement for ethical review. It isn't known how much research on human subjects occurs without review by government officials or IRBs. But such research may expose patients to unnecessary risks.

In 1999, the review-board system came under some scrutiny when 18-year-old Jesse Gelsinger died during a gene-therapy trial at the University of Pennsylvania in Philadelphia. In 2001, a healthy woman died after taking an unapproved asthma medication during a clinical trial at Johns Hopkins University. And looking farther afield, in London last year six men became seriously ill during a clinical trial of a monoclonal-antibody therapy.

Overall, it is not a bad record. But that is as much by luck as by design, and if it is to remain the case, real improvements need to be made to the IRB system. The impetus for such change should not have to rely on the bursts of interest that tend to follow mishaps during human trials.

\section{A sporting chance}

\section{Bans on drug enhancement in sport may go the way} of earlier prohibitions on women and remuneration.

W hether you have been following the just-finished Tour de France or waiting for Barry Bonds to break the all-time record for major-league home runs in baseball, the topic of drugs in sport has been hard to avoid of late.

To cheat in a sporting event is a loathsome thing. For as long as the rules of the Tour de France or any sporting event ban the use of performance-enhancing drugs, those who break the rules must be punished whenever possible. But this does not preclude the idea that it may, in time, be necessary to readdress the rules themselves.

As more is learned about how our bodies work, more options become available for altering those workings. To date, most of this alteration has sought to restore function to some sort of baseline. But it is also possible to enhance various functions into the supernormal realm, and the options for this are set to grow ever greater.

The fact that such endeavours will carry risks should not be trivialized. But adults should be allowed to take risks, and experience suggests that they will do so when the benefits on offer are enticing enough. By the end of this century the unenhanced body or mind may well be vanishingly rare.

As this change takes place, we will have to re-examine what we expect of athletes. If spectators are seeking to reset their body mass index through pharmacology, or taking pills that enhance their memory, is it really reasonable that athletes should make do with bodies that have not seen such benefits? The more the public comes to live with the mixed and risk-related benefits of enhancement, the more it will appreciate that allowing such changes need not rob sport of its drama, nor athletes of their need for skill, training, character and dedication.
To change the rules on pharmacological enhancement would not be without precedent. It was once thought that a woman could not epitomize the athletic ideal as a man could, and so should be stopped from trying. Similarly, it was thought proper to keep all payments from some athletes, thus privileging the already wealthy. These prejudices have been left behind, and the rules have changed. As pharmacological enhancement becomes everyday, views of bodily enhancement may evolve sufficiently for sporting rules to change on that, too.
"Is it really reasonable that athletes should make do with bodies that have not been enhanced?"
This transition will not be painless. Some people will undoubtedly harm themselves through the use of enhancements, and there would need to be special protection for children. That said, athletes harm themselves in other forms of training, too. They may harm themselves less with drugs when doctors can be openly involved and masking agents dispensed with.

There is also the problem of who goes first. The first sport to change its rules to allow players to use performance-enhancing drugs will be attacked as a freak show or worse. The same may be true of the second. This may well have the effect - may already be having the effect - of delaying the inevitable.

Perhaps the Tour de France could show the way ahead here. In terms of public respect, endurance cycling has the least to lose and perhaps the most to gain. To be sure, a change in the rules would lead to the claim that 'the cheats have won'. But as no one can convincingly claim that cheats are not winning now, or have not been winning in the past, that claim is not quite the showstopper it might seem to be.

A leadership ready to ride out the outrage might be better for the sport in the long run. If some viewers and advertisers were lost along the way, the Tour could console itself with the thought that it got by with far less commercial interest in days gone by - and that it is more likely to re-establish itself through excellence and honesty than in the penumbra of doubt and cynicism that surrounds it now. 